\title{
Improvement in Surface Roughness and Hardness for Carbon Steel by Slide Burnishing Process
}

\author{
Hirotaka Kato $^{1 *}$, Wataru Hirokawa ${ }^{1}$, Yoshikazu Todaka ${ }^{2}$, Kazufumi Yasunaga ${ }^{3}$ \\ ${ }^{1}$ Department of Mechanical Engineering, Fukui College, National Institute of Technology, Sabae, Japan \\ ${ }^{2}$ Department of Mechanical Engineering, Toyohashi University of Technology, Toyohashi, Japan \\ ${ }^{3}$ Research and Development Department, The Wakasa Wan Energy Research Center, Tsuruga, Japan \\ Email: ${ }^{\star}$ hkato@fukui-nct.ac.jp
}

How to cite this paper: Kato, H., Hirokawa, W., Todaka, Y. and Yasunaga, K. (2021) Improvement in Surface Roughness and Hardness for Carbon Steel by Slide Burnishing Process. Materials Sciences and Applications, 12, 171-181. https://doi.org/10.4236/msa.2021.125011

Received: March 26, 2021

Accepted: May 5, 2021

Published: May 8, 2021

Copyright $\odot 2021$ by author(s) and Scientific Research Publishing Inc. This work is licensed under the Creative Commons Attribution International License (CC BY 4.0).

http://creativecommons.org/licenses/by/4.0/

\section{(c) (i) Open Access}

\begin{abstract}
Slide burnishing process, which is a surface severe plastic deformation technique, offers an attractive post-machining alternative due to its chip-less and relatively simple operations. The purpose of the present work is to investigate effects of initial turned surface roughness on the burnished surface roughness and hardness in slide burnishing. The carbon steel samples those have different roughness surfaces being treated were prepared by turning by varying the feed. Slide burnishing was then carried out by a silicon nitride ceramic ball that was loaded and fed on the turned surface of a rotating specimen using a lathe machine. It was found that the turned surfaces were smoothed drastically by the burnishing process, and that the $\mathrm{Ra}$ and $\mathrm{Rz}$ values were reduced at most by a factor of 52 and 21, respectively. However, the smoothing effect of burnishing has limit, and the limited maximum height roughness $\left(\mathrm{Rz}^{\star}\right)$ for burnishing smoothing increased under a higher burnishing force and with a larger ball diameter. When the $\mathrm{Rz}$ values of initial turned surfaces were less than the $\mathrm{Rz}^{\star}$, the roughness of the burnished surfaces did not depend on the roughness of the initial turned surface and the burnishing force. There was no significant difference in the burnished microstructure and hardness under a specific burnishing force among the initial turned surface roughness, while a higher burnishing force caused a greater increase in surface hardness.
\end{abstract}

\section{Keywords}

Burnishing, Turning, Surface Smoothing, Roughness, Hardness, Carbon Steel

\section{Introduction}

Machined surfaces by conventional processes such as turning and milling have 
inherent irregularities like tool marks and scratches that cause tribological problems (friction and wear). To overcome these complications, conventional finishing processes such as grinding, honing and lapping have been traditionally employed [1]. However, since these methods essentially depend on chip removal to attain the desired surface finish, these machining chips may cause further surface abrasion and geometric tolerance problem. Accordingly, burnishing process offers an attractive post-machining alternative due to its chip-less and relatively simple operations. Burnishing process is a surface severe plastic deformation technique, in which the surface of the workpiece is subject to compressing and rubbing (or rolling) by the application of a ball, roller and hemispherical tip as a tool [2]. This process provides many advantages; burnishing generates a smooth surface by plastic deformation of surface irregularities without removal of material from the surface, and increases the surface hardness of the workpiece due to the microstructural evolution such as grain refinement, which in turn improves the wear resistance, and improves the fatigue strength by inducing residual compressive stresses in the surface [3]. Moreover, this method does not require special equipment, because it can be performed using the same machine tools as those commonly used for cutting [4].

Burnishing processes are classified into two groups according to the type of the contact between the tool and the surface being treated: roll (or roller/ball) burnishing and slide burnishing [5]. Roll burnishing is a process in which a roller or ball is pressed and rolled (without slipping) on the surface, and then the contact is rolling friction [1] [2] [3] [4] [6]. On the other hand, slide burnishing is a process in which a fixed tool is pressed and slid on the surface of a rotating workpiece, and then the contact is sliding friction [7]-[12]. In slide burnishing, friction-induced plastic deformation and very large strains can be introduced to the material surface, leading to grain refinement and nano-crystallization [8] [12] [13] [14].

Many authors have been studying the effects of burnishing parameters, such as burnishing force, burnishing feed, burnishing speed and number of burnishing tool passes [1] [2] [3] [4] [6] [7] [9] [11] [13] [14]. However, little work has been done to study effects of the initial surface finish, while Korzynski [10] has suggested that the surface smoothing process in burnishing depends on the initial roughness of a workpiece based on a theoretical analysis of an assumed slide burnishing model. Hassan and Maqableh [15] have showed that final burnished surface roughness of brass increased linearly with increase in the initial surface roughness in roll burnishing. Unfortunately, experimental work concerning effects of initial surface finish in slide burnishing has been limited. The present work was then carried out on a carbon steel to investigate effects of initial turned surface roughness on the burnished surface roughness and hardness in slide burnishing.

\section{Experimental}

\subsection{Sample Preparation}

The work-material in the present study was a normalized carbon steel $(0.42-$ 
$0.48 \mathrm{C}, 0.15-0.35 \mathrm{Si}, 0.60-0.90 \mathrm{Mn},<0.03 \mathrm{P},<0.035 \mathrm{~S}$, bal. Fe, mass \%) with a hardness of HV 250. This steel is widely used in mechanical industries. Samples were first prepared by turning in a disc shape of $60 \mathrm{~mm}$ diameter and $5 \mathrm{~mm}$ thickness. In disc-shaped parts, the end surface should be smoothed for application. The end surface, which is to be treated, was finished using cemented carbide (WC-Co) tip with a tip radius of $0.4 \mathrm{~mm}$ in different roughness by varying the tip feed such as $0.1,0.2,0.3,0.4$ and $0.5 \mathrm{~mm} / \mathrm{rev}$. (revolution). The rotation speed of the disc was $560 \mathrm{rpm}$, and the cutting depth was $0.5 \mathrm{~mm}$. The maximum height roughness $(\mathrm{Rz})$ of the turned end surfaces was changed in the range of 7.8 to $65.5 \mu \mathrm{m}$ according to the tip feed.

\subsection{Burnishing Method}

Slide burnishing was performed by a nonrotating ball that was loaded and fed on the end surface of a rotating disk specimen. The ball was made of silicon nitride ceramic $\left(\mathrm{Si}_{3} \mathrm{~N}_{4}\right)$, and the ball surface was polished to a mirror shine. The reason for choice of this material for a ball was that preliminary experimental results showed silicon nitride ceramic was the best material for improvement in surface roughness. Figure 1 shows the experimental setup for the burnishing process in this study. The disk specimen was rotated by the main spindle of a lathe through a jig (disc holder). The end surface of the disc was subject to a compressive force by the ball, which was held by a ball holder. The ball holder was elastically supported by a helical compression spring which was located inside a loading adapter, and the loading adapter was held to the shank, which was fixed on the lathe tool post. The applied burnishing force, which was caused by the compression of the spring, was controlled with a three-axis force dynamometer at the interface between the shank and the tool post of the lathe. The ball was fed automatically in a transverse direction by a feeding mechanism of the lathe. The burnishing parameters considered are given in Table 1 . The track diameter of the burnished area of the disk end surface was from $38 \mathrm{~mm}$ to $52 \mathrm{~mm}$. All burnishing treatments were carried out at ambient temperature in air.

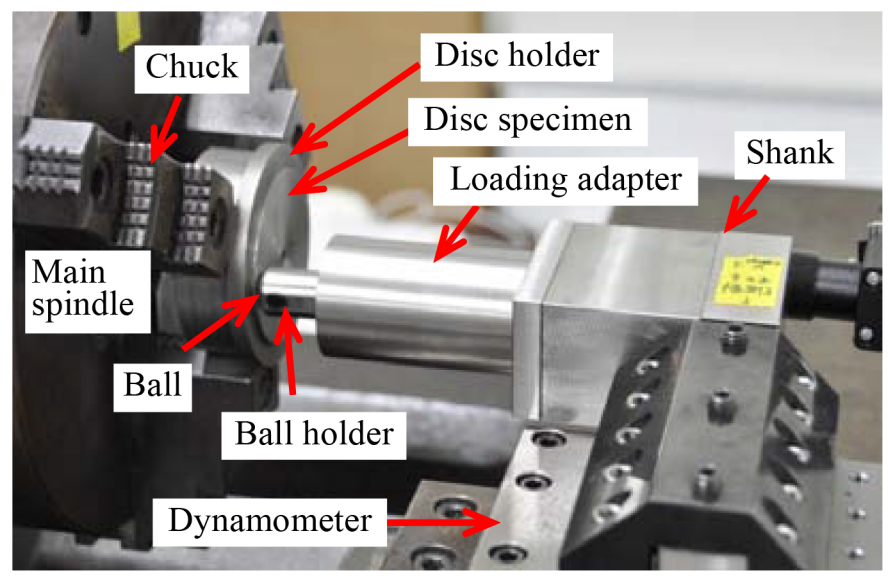

Figure 1. Experimental setup view for burnishing. 
Table 1. Summary of burnishing parameters.

\begin{tabular}{cc}
\hline Parameters & Values \\
\hline Ball diameter $(\mathrm{mm})$ & $6.35,12.7$ \\
Burnishing force $(\mathrm{N})$ & 250,500 \\
Rotation speed of sample (rpm) & 800 \\
Burnishing feed (mm/rev.) & 0.01 \\
Lubricant & None \\
Number of tool passes & 1 \\
\hline
\end{tabular}

\subsection{Measurement of Surface Roughness and Hardness}

Initial turned surfaces (before burnishing) and final burnished surfaces were observed by a digital microscope (Keyence VHX-900). The roughness of both the surfaces was measured by a stylus using a profilometer (Mitutoyo Surftest SJ-410). All the measurements were carried out with a cutoff length of $0.25 \mathrm{~mm}$ and in each case the average of three readings was used.

The surface hardness was examined using a Vickers micro-hardness testing machine (Mitutoyo HM-102) with an applied load of $3 \mathrm{~N}$. The average value of five measurements for each specimen was recorded. Metallographic structures were observed with an optical microscope (Nikon XPF-uNR-B) in a sub-surface longitudinal cross-section of the burnished specimen. A Vickers micro-hardness was also measured at the sub-surface cross-section under an applied load of 0.1 $\mathrm{N}$.

\section{Results and Discussion}

\subsection{Surface Roughness}

Figure 2 shows examples of microscope images, surface roughness parameters $\mathrm{Ra}$ (arithmetic average roughness) and $\mathrm{Rz}$ (maximum height roughness), and surface profile graphs generated by a stylus for the turned surfaces (before burnishing) and turned and burnished surfaces. The burnishing in this figure was carried out under the conditions of a ball diameter of $12.7 \mathrm{~mm}$ and a burnishing force of $250 \mathrm{~N}$. It is seen clearly that tool marks are formed in the initial turned surfaces and that the Ra and $\mathrm{Rz}$ values of the turned surfaces increased with increase of the turning feed. This means that the shape of the turning tip was transferred in the surface texture.

After burnishing, the surfaces were smoothed drastically. When the turning feed was in the range of 0.1 to $0.4 \mathrm{~mm} / \mathrm{rev}$., no turning tool marks remained in the burnished surfaces. Since the applied burnishing pressure exceeds the yield strength of the material, the asperities of the surface deform plastically and spread out permanently to fill the valleys [1]. For a turning feed of $0.4 \mathrm{~mm} / \mathrm{rev}$., the burnishing process reduced the $\mathrm{Ra}$ and $\mathrm{Rz}$ values by a factor of 52 and 21 , respectively. However, when the turning feed was $0.5 \mathrm{~mm} / \mathrm{rev}$., the valleys of the turning tool marks of the initial turned surface remained in the final burnished 


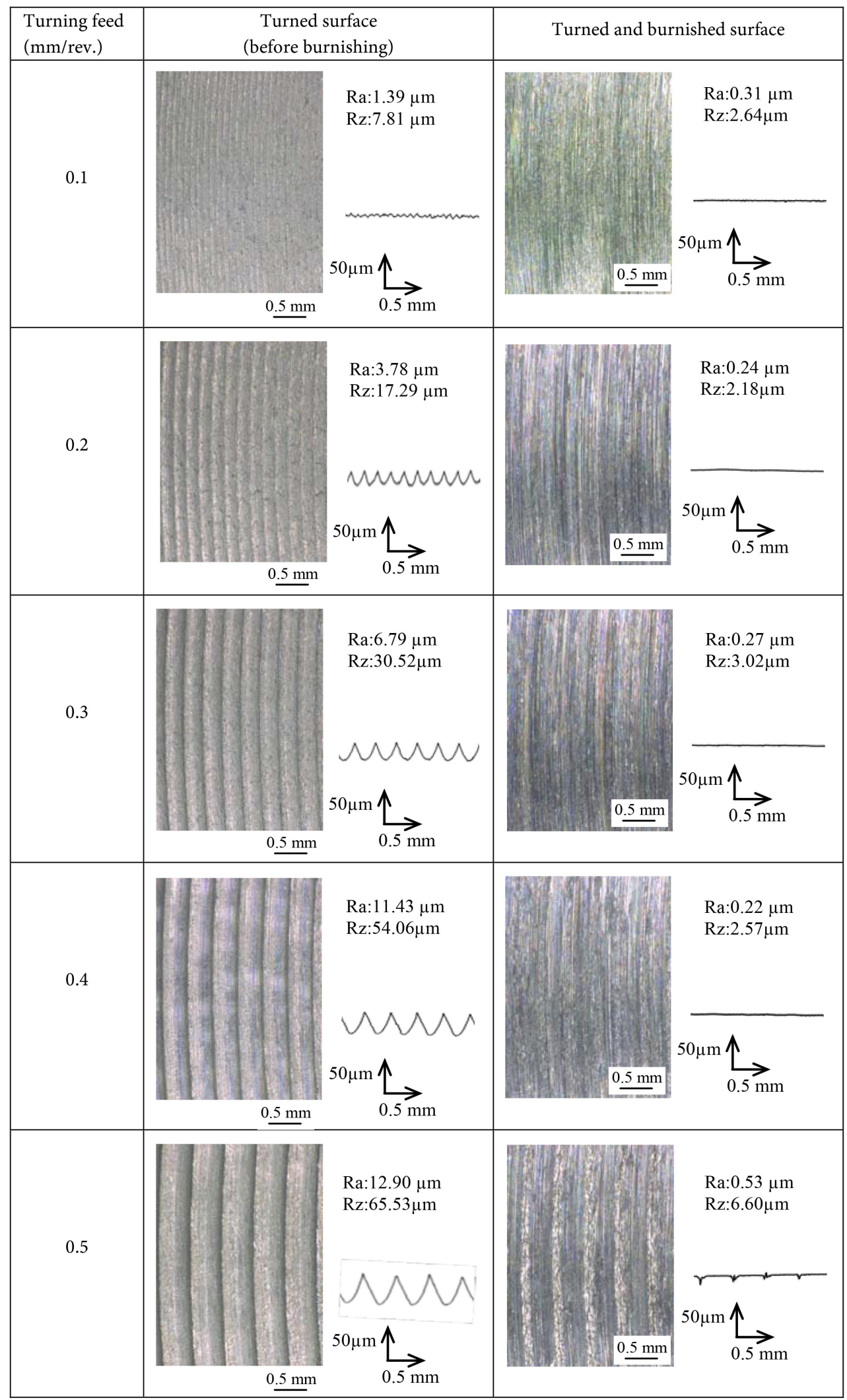

Figure 2. Microscope images, surface roughness parameters (Ra: arithmetic average roughness, Rz: maximum height roughness) and surface profile graphs for turned surfaces and burnished surfaces under burnishing conditions of ball diameter of $12.7 \mathrm{~mm}$ and burnishing force of $250 \mathrm{~N}$. 
surface. Because the valleys of the asperities are relatively large, i.e., a large value of $\mathrm{Rz}$ in the initial turned surface, the deforming by burnishing force is not enough to smooth them completely, which will cause a relative increase in the surface roughness [15].

Figure 3 shows the relationship between $\mathrm{Rz}$ of the initial turned surfaces and $\mathrm{Ra}$ of the final burnished surfaces. Maximum height of the profile $(\mathrm{Rz})$ of the turned surface is used rather than $\mathrm{Ra}$ as a horizontal axis, because it will affect smoothing mechanism of burnishing [10]. We have found that smoothing effect of burnishing has limit. When the ball diameter was $6.35 \mathrm{~mm}$ and the burnishing force was $250 \mathrm{~N}$, for example, the burnishing process was able to smooth the turned surfaces that had $\mathrm{Rz}$ values up to $31 \mu \mathrm{m}$ (Figure 3(a)). In this situation the Ra values of the burnished surfaces were almost constant at $0.2 \mu \mathrm{m}$ and did not depend on the $\mathrm{Rz}$ of the turned surface. As the $\mathrm{Rz}$ value of the turned surface exceeded $31 \mu \mathrm{m}$, Ra values of the burnished surfaces increased. In this case, the limited maximum height roughness $\left(\mathrm{Rz}^{*}\right)$ for burnishing smoothing was $31 \mu \mathrm{m}$. At a higher burnishing force of $500 \mathrm{~N}$, the $\mathrm{Rz}^{*}$ value was $48 \mu \mathrm{m}$. This means that a much amount of deformation occurred on the surface under the condition of a higher burnishing force, resulting in a higher value of $\mathrm{Rz}^{\star}$. Again the $\mathrm{Ra}$ values of the burnished surfaces were almost constant at $0.2 \mu \mathrm{m}$ and did not depend on the $\mathrm{Rz}$ of the turned surface.

Figure 3(b) presents the results in the case of $12.7 \mathrm{~mm}$ of a ball diameter. We can see that the burnishing by a larger ball enabled much rougher surfaces to smooth. This is due to the large contact area between the ball and the disc specimen in the burnishing with a large ball diameter under a specific burnishing force. Thus, we have concluded that the $\mathrm{Rz}^{*}$ increased under a higher burnishing force and with a larger ball diameter, and that when the $\mathrm{Rz}$ values of turned surfaces were less than the $\mathrm{Rz}^{*}$ the roughness of the burnished surfaces did not depend on the roughness of the initial turned surface and the burnishing force. This was not in agreement with the previous work which have reported that in

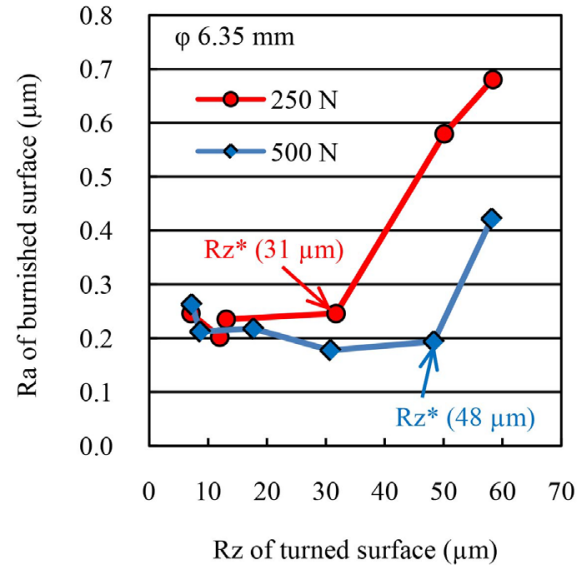

(a)

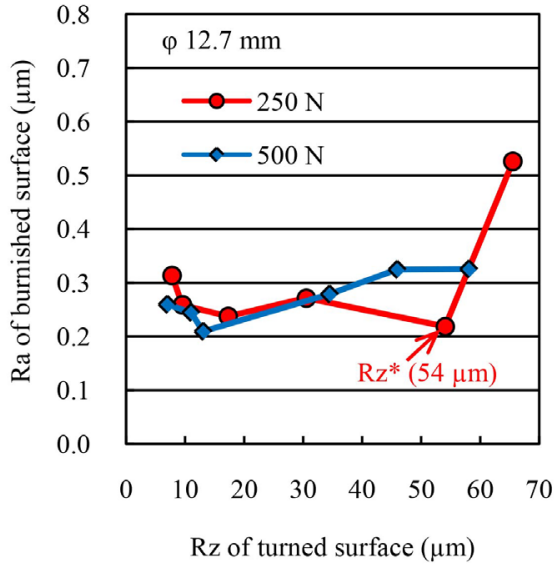

(b)

Figure 3. Relationship between $\mathrm{Rz}$ of initial turned surfaces and $\mathrm{Ra}$ of final burnished surfaces under burnishing conditions of ball diameter of (a) $6.35 \mathrm{~mm}$ and (b) $12.7 \mathrm{~mm}$. 
ball burnishing the final burnished surface roughness increased with increase in the initial surface roughness and decreased with increase in the burnishing force [15]. This seems to be due to the difference in smoothing mechanism between ball burnishing and slide burnishing.

\subsection{Microstructure and Hardness}

Figure 4 shows examples of optical microstructure and Vickers hardness of a sub-surface longitudinal cross-section for burnished specimens. These burnishing processes were conducted with a ball diameter of $6.35 \mathrm{~mm}$. Plastic flow structures in which grains were inclined and elongated to the friction direction in the burnishing process were generated. There was no significant difference in the microstructure between the turning feeds of $0.1 \mathrm{~mm} / \mathrm{rev}$. (Figure $4(\mathrm{a})$ and Figure $4(\mathrm{~b})$ ) and $0.5 \mathrm{~mm} / \mathrm{rev}$. (Figure 4 (c) and Figure 4(d)), which means that the initial surface roughness has no influence on the burnished microstructure. If we look at the effect of the burnishing force, plastic deformation occurred in a much deeper region under a high force of $500 \mathrm{~N}$ (Figure 4(b) and Figure 4(d)) in comparison with a low force of $250 \mathrm{~N}$ (Figure 4(a) and Figure 4(c)).

Figures 5(a)-(d) are Vickers hardness profiles of the sub-surface cross-sections

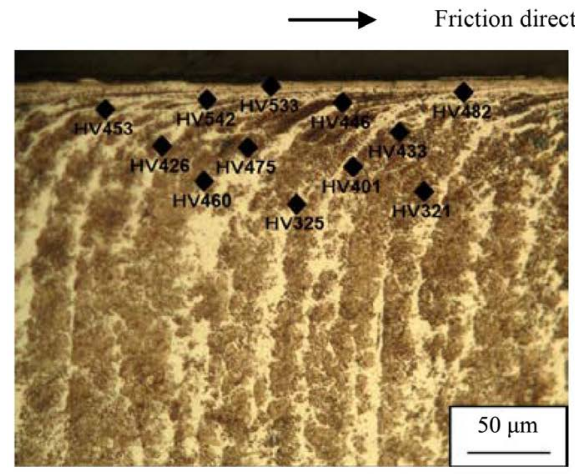

(a)

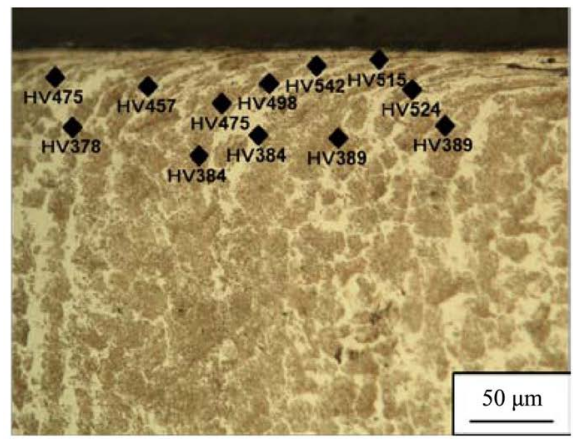

(c)

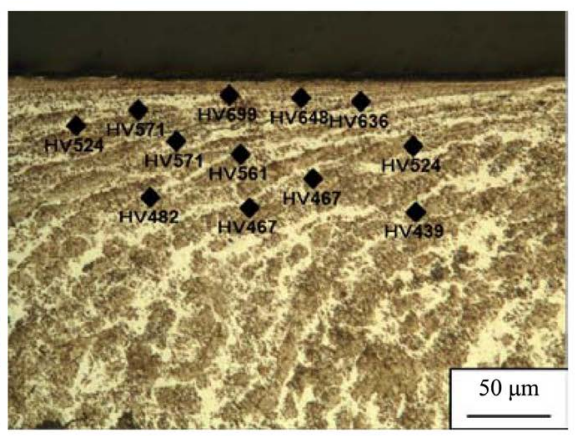

(b)

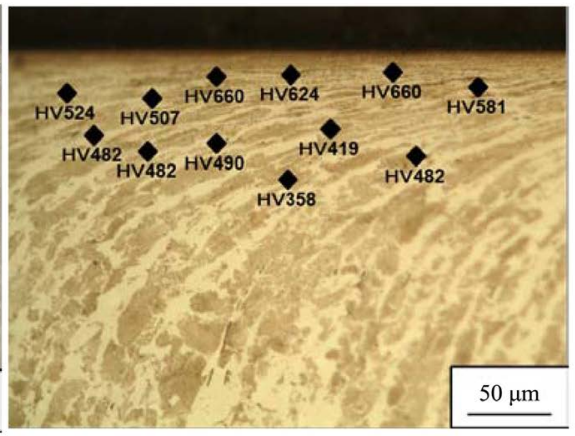

(d)

Figure 4. Optical microstructure and Vickers hardness of a sub-surface longitudinal cross-section for burnished specimens under a burnishing condition of ball diameter of $6.35 \mathrm{~mm}$. (a) Turning feed: $0.1 \mathrm{~mm} / \mathrm{rev}$., Burnishing force: $250 \mathrm{~N}$, (b) Turning feed: 0.1 $\mathrm{mm} / \mathrm{rev}$. , Burnishing force: $500 \mathrm{~N}$, (c) Turning feed: $0.5 \mathrm{~mm} / \mathrm{rev}$., Burnishing force: 250 $\mathrm{N}$, (d) Turning feed: $0.5 \mathrm{~mm} / \mathrm{rev}$., Burnishing force: $500 \mathrm{~N}$. 


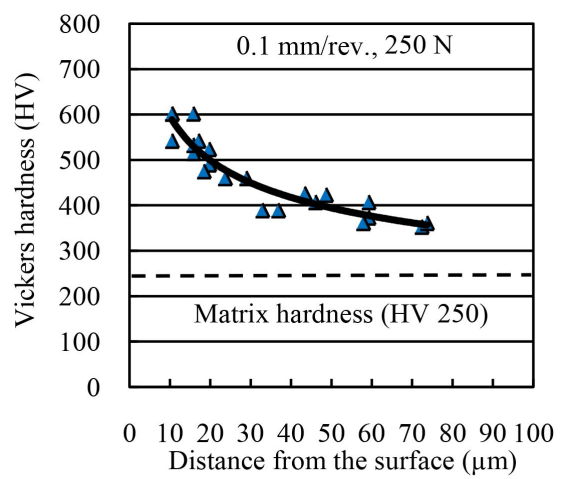

(a)

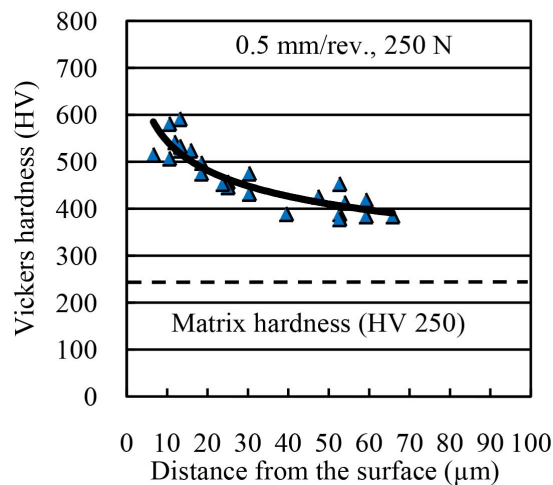

(c)

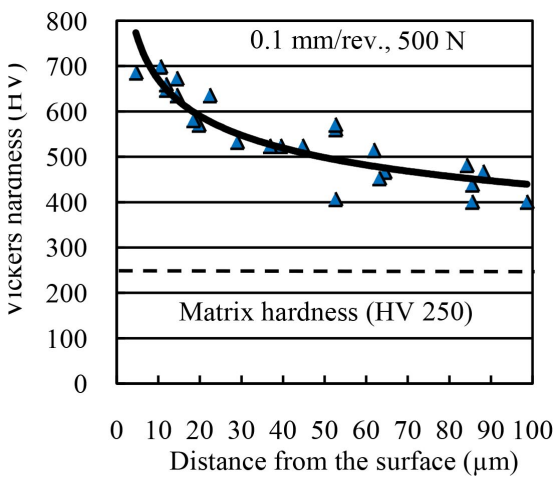

(b)

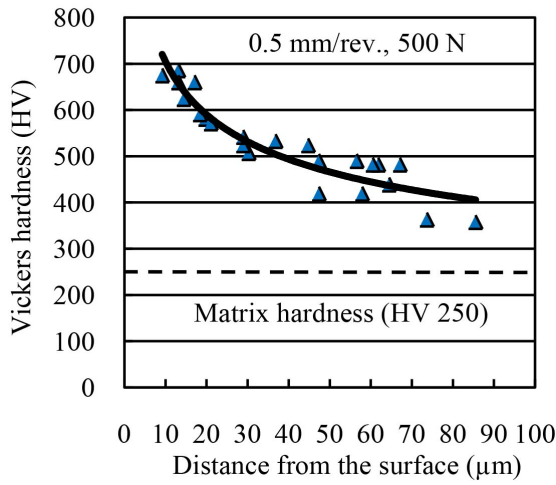

(d)

Figure 5. Vickers hardness profile of a sub-surface cross-section for burnished specimens under a burnishing condition of ball diameter of $6.35 \mathrm{~mm}$. (a) Turning feed: $0.1 \mathrm{~mm} / \mathrm{rev}$., Burnishing force: $250 \mathrm{~N}$, (b) Turning feed: $0.1 \mathrm{~mm} / \mathrm{rev}$., Burnishing force: $500 \mathrm{~N}$, (c) Turning feed: $0.5 \mathrm{~mm} / \mathrm{rev}$., Burnishing force: $250 \mathrm{~N}$, (d) Turning feed: $0.5 \mathrm{~mm} / \mathrm{rev}$., Burnishing force: $500 \mathrm{~N}$.

which are correspond to the burnished specimens that are shown in Figures 4 (a)-(d) respectively. In these graphs, hardness values are plotted against the distance from the surface. The hardness significantly increased as the surface was approached. This was caused by an increase of the dislocation density of the microstructure and the grain refinement due to the friction-induced plastic deformation. As mentioned before, there was no significant difference between the turning feeds, whereas higher hardness was observed at a deeper region from the surface under a higher burnishing force of $500 \mathrm{~N}$.

Figure 6(a) and Figure 6(b) show effects of the Rz of turned surfaces on the burnished surface hardness under burnishing conditions of the ball diameters of $6.35 \mathrm{~mm}$ and $12.7 \mathrm{~mm}$, respectively. A reason for the relatively low surface hardness compared with the hardness at the near surface shown in Figure 5 seems to be due to the difference of the testing load in Vickers hardness examinations. It can be seen that the initial turned surface roughness does not cause a significant change in surface hardness under a constant burnishing force, because the amount of surface deformation is nearly the same if the burnishing force is constant, regardless of the initial surface roughness of the workpiece 


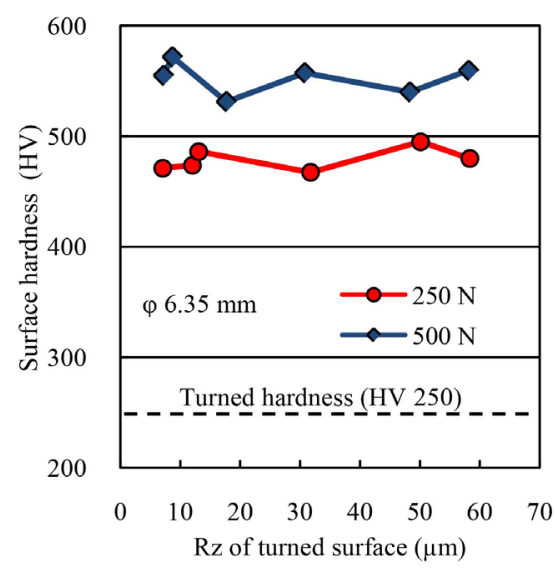

(a)

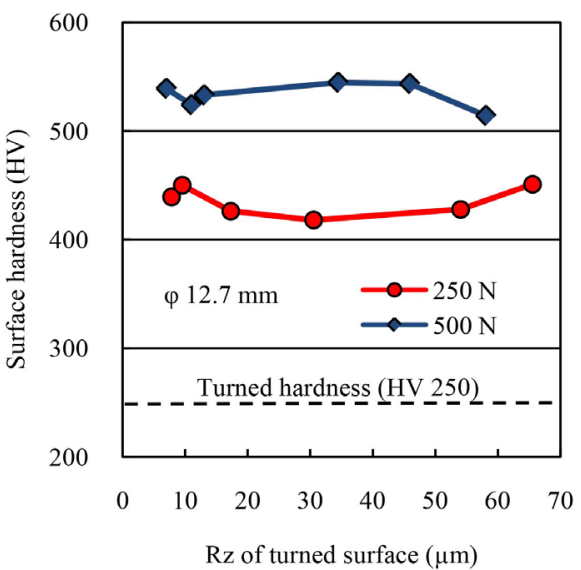

(b)

Figure 6. Effects of $\mathrm{Rz}$ of turned surface on burnished surface hardness under burnishing conditions of ball diameter of (a) $6.35 \mathrm{~mm}$ and (b) $12.7 \mathrm{~mm}$.

[15]. As was expected, the higher burnishing force caused a greater increase in surface hardness clearly, and the surface hardness for the burnishing force of 500 $\mathrm{N}$ was more than two times higher compared with the initial hardness of the turned surface.

It was observed also from these figures that a lesser increase in hardness was obtained with a large ball diameter under a specific burnishing force. Since the contact area of the ball with the surface increases with increase in the burnishing ball diameter, the contact pressure between the ball and the surface decreases under a specific burnishing force. This means that a lesser amount of deformation occurs on the surface of the workpiece, causing a lesser increase in hardness [15].

\section{Conclusions}

The present work was conducted to investigate effects of initial turned surface roughness on the burnished surface roughness and hardness in slide burnishing. The carbon steel samples those have different roughness surfaces being treated were prepared by turning by varying the feed. Slide burnishing was carried out by a silicon nitride ceramic ball that was loaded and fed on the turned surface of a rotating specimen using a lathe machine. The following conclusions were derived from the results:

1) The turned surfaces were smoothed drastically by the burnishing process, and the $\mathrm{Ra}$ and $\mathrm{Rz}$ values were reduced at most by a factor of 52 and 21, respectively.

2) The smoothing effect of burnishing has limit, and the limited maximum height roughness $\left(\mathrm{Rz}^{*}\right)$ for burnishing smoothing increased under a higher burnishing force and with a larger ball diameter.

3) When the $\mathrm{Rz}$ values of initial turned surfaces were less than the $\mathrm{Rz}^{*}$, the roughness of the burnished surfaces did not depend on the roughness of the initial turned surface and the burnishing force. 
4) Plastic flow structures in which grains were inclined and elongated to the friction direction in the burnishing process were generated at the sub-surface. There was no significant difference in the burnished microstructure and hardness under a specific burnishing force among the initial turned surface roughness, while a higher burnishing force caused a greater increase in surface hardness.

\section{Acknowledgements}

This work was supported in part by a Grant-in-Aid for Scientific Research from the Ministry of Education, Culture, Sports, Science and Technology of Japan (Grant No.: 19K04160).

\section{Conflicts of Interest}

The authors declare no conflicts of interest regarding the publication of this paper.

\section{References}

[1] El-Tayeb, N.S.M., Low, K.O. and Brevern, P.V. (2007) Influence of Roller Burnishing Contact Width and Burnishing Orientation on Surface Quality and Tribological Behaviour of Aluminium 6061. Journal of Materials Processing Technology, 186, 272-278. https://doi.org/10.1016/j.jmatprotec.2006.12.044

[2] Revankar, G.D., Shetty, R., Rao, S.S. and Gaitonde, V.N. (2017) Wear Resistance Enhancement of Titanium Alloy (Ti-6Al-4V) by Ball Burnishing Process. Journal of Materials Research and Technology, 6, 13-32. https://doi.org/10.1016/j.jmrt.2016.03.007

[3] Hassan, A.M. and Al-Bsharat, A.S. (1996) Influence of Burnishing Process on Surface Roughness, Hardness, and Microstructure of Some Non-Ferrous Metals. Wear, 199, 1-8. https://doi.org/10.1016/0043-1648(95)06847-3

[4] Okada, M., Suenobu, S., Watanabe, K., Yamashita, Y. and Asakawa, N. (2015) Development and Burnishing Characteristics of Roller Burnishing Method with Rolling and Sliding Effects. Mechatronics, 29, 110-118.

https://doi.org/10.1016/j.mechatronics.2014.11.002

[5] Maximov, J.T., Duncheva, G.V., Anchev, A.P. and Ichkova, M.D. (2019) Slide Burnishing-Review and Prospects. The International Journal of Advanced Manufacturing Technology, 104, 785-801. https://doi.org/10.1007/s00170-019-03881-1

[6] Chomienne, V., Valiorgue, F., Rech, J. and Verdu, C. (2016) Influence of Ball Burnishing on Residual Stress Profile of a 15-5PH Stainless Steel. CIRP Journal of Manufacturing Science and Technology, 13, 90-96. https://doi.org/10.1016/j.cirpj.2015.12.003

[7] Nestler, A. and Schubert, A. (2015) Effect of Machining Parameters on Surface Properties in Slide Diamond Burnishing of Aluminium Matrix Composites. Materials Today Proceedings, 2S, S156-S161. https://doi.org/10.1016/j.matpr.2015.05.033

[8] Li, W.L., Tao, N.R., Han, Z. and Lu, K. (2012) Comparisons of Dry Sliding Tribological Behaviors between Coarse-Grained and Nanocrystalline Copper. Wear, 274-275, 306-312. https://doi.org/10.1016/j.wear.2011.09.010

[9] Maximov, J.T., Duncheva, G.V., Anchev, A.P., Ganev, N., Amudjev, I.M. and Dun- 
chev, V.P. (2018) Effect of Slide Burnishing Method on the Surface Integrity of AISI 316Ti Chromium-Nickel Steel. Journal of the Brazilian Society of Mechanical Sciences and Engineering, 40, 194. https://doi.org/10.1007/s40430-018-1135-3

[10] Korzynski, M. (2009) A Model of Smoothing Slide Ball-Burnishing and an Analysis of the Parameter Interaction. Journal of Materials Processing Technology, 209, 625-633. https://doi.org/10.1016/j.jmatprotec.2008.02.037

[11] Lin, Y.C., Wang, S.W. and Lai, H.-Y. (2004) The Relationship between Surface Roughness and Burnishing Factor in the Burnishing Process. The International Journal of Advanced Manufacturing Technology, 23, 666-671. https://doi.org/10.1007/s00170-002-1486-9

[12] Pang, C., Luo, H., Zhang, Z. and Ma, Y. (2018) Precipitation Behavior and Grain Refinement of Burnishing Al-Zn-Mg Alloy. Progress in Natural Science: Materials International, 28, 54-59. https://doi.org/10.1016/j.pnsc.2017.11.006

[13] Kato, H., Yamamoto, K. and Yasunaga, K. (2020) Nano-Crystallization of Steel Surface by Slide-Burnishing. Key Engineering Materials, 841, 48-53. https://doi.org/10.4028/www.scientific.net/KEM.841.48

[14] Zhang, X., Luo, H., Han, Z. and Lv, J. (2014) Evolution of Microstructures and Texture in the Surface Layer of Copper during Burnishing Process. Materials Science and Technology, 30, 1742-1750. https://doi.org/10.1179/1743284713Y.0000000463

[15] Hassan, A.M. and Maqableh, A.M. (2000) The Effects on Initial Burnishing Parameters on Non-Ferrous Components. Journal of Materials Processing Technology, 102, 115-121. https://doi.org/10.1016/S0924-0136(00)00464-7 